\title{
Composição Corporal e Exigências de Energia e Proteína para Ganho de Peso de Bovinos de Quatro Raças Zebuínas ${ }^{1}$
}

\author{
Mário Fonseca Paulino², Carlos Augusto de Alencar Fontes ${ }^{3}$, André Mendes Jorge ${ }^{4}$, Paulo \\ Gomes Júnior ${ }^{5}$
}

\begin{abstract}
RESUMO - A composição corporal e as exigências de energia e proteína para ganho de peso de bovinos de quatro raças zebuínas (Gir, Guzerá, Mocho-Tabapuã e Nelore) foram estimadas com 63 animais não-castrados, com idade média de 24 meses e peso vivo inicial de 366 kg. Dezesseis animais das raças Gir, Guzerá e Mocho-Tabapuã e 15 da raça Nelore. Quinze animais, quatro das raças Gir, Guzerá e Mocho-Tabapuã e três da raça Nelore, foram abatidos no início do estudo e os demais, distribuídos em três grupos, com três animais de cada raça e alimentados individualmente, ad libitum, com ração contendo $50 \%$ de concentrado (\%MS), até atingirem peso vivo de abate de 405, 450 e $500 \mathrm{~kg}$, respectivamente. Regressão do logaritmo do conteúdo corporal de energia, gordura e proteína, em função do logaritmo do corpo vazio (PCVZ), foi ajustada, possibilitando estimar a composição corporal total dos constituintes para qualquer PCVZ dentro do intervalo incluido na pesquisa ( 250 a $450 \mathrm{~kg}$ ). Pela derivação das equações, a composição do ganho de PCVZ foi obtida. Os animais das quatro raças não diferiram quanto à composição corporal de gordura, proteína e energia. As exigências de proteína e energia líquidas para ganho de peso obtidas foram semelhantes às adotadas pelo NRC (1996) e as de energia metabolizável, às adotadas pelo AFRC (1993).
\end{abstract}

Palavras-chave: energia, proteína, ganho de peso, raças zebuínas

\section{Body Composition and Energy and Protein Requirements for Weight Gain of Bulls from Four Zebu Breeds}

\begin{abstract}
The body composition and the requirements for weight gain of energy and protein of cattle from four Zebu breeds (Gyr, Guzera, Mocho-Tabapuã and Nellore) were estimated with 63 bulls averaging 24 months of age and $366 \mathrm{~kg}$ LW initial. Fifteen animals, four from Gyr, Guzera and Mocho-Tabapuã breed and three from Nellore breed, were slaughtered at the beginning of the trial and the remaining were allotted to three groups, with three animals from each breed, which were individually full fed a diet containing 50\% concentrate ( $\% \mathrm{DM})$, to reach target live weights of 405, 450 and $500 \mathrm{~kg}$, respectively. Regression of the log of body content in energy, fat, and protein on log of the empty body weight (EBW) was fitted to estimate the total body content of those constituents for any EBW inside the range included in the research (250 to $450 \mathrm{~kg}$ ). By differentiation of those regressions, the composition of EBW weight gain was rejusted. The animals from the four breeds did not differ regarding to body composition of fat, protein and energy. The requirements of protein and net energy for the rejusted weight gains were similar to the adopted by NRC (1996) and the metabolizable energy as the adopted by AFRC (1993).
\end{abstract}

Key Words: energy, protein, weight gain, Zebu breed

\section{Introdução}

As diferenças nas exigências de energia para ganho, entre animais de raças diferentes, devem-se a diferenças na composição do ganho de peso (GARRET et al, 1959). O conteúdo de gordura no ganho de peso é influenciado por fatores como raça, sexo, peso corporal e nível de ganho (GEAY, 1984).

GARRETT (1980) afirma que a raça tem influência muito mais marcante sobre a composição corporal, a um mesmo peso vivo ou peso de carcaça, que o nível de nutrição. Para o ARC (1980), a raça e o sexo influenciam mais a composição do ganho de peso que o nível de ganho de peso diário. A composição do ganho de peso é, também, influenciada pela aptidão leiteira ou de corte do animal (PERON et al., 1993a, b).

Os requerimentos de energia líquida para ganho de peso (ELg) são estimados como a quantidade de energia depositada como matéria orgânica não-gordurosa (a maior parte proteína) mais aquela depositada como gordura (NRC, 1984). O NRC (1984) estima os requerimentos de energia para ganho com base no peso e ganho de peso diário. Ajustes são feitos para

\footnotetext{
1 Parte da Tese apresentada pelo primeiro autor à UFV para obtenção do título de "Doctor Scientiae". Trabalho realizado na UFV em colaboração com a EPAMIG e FAPEMIG.

2 Professor da UFV. Bolsista do CNPq

3 Professor Titular - UENF - LZNA/CCTA, Campos, RJ

4 Pesquisador Científico do Instituto de Zootecnia. EEZ-VR.

${ }^{5}$ Estudante de Mestrado da UFV.
} 
condições específicas, como classe de sexo, tamanho do animal, uso de implantes ou hormônios. A magnitude das modificações necessárias é relacionada a diferenças na composição do corpo relativo a peso e idade e a influência destas variáveis sobre a utilização de energia.

Para o AFRC (1993), o requerimento de energia metabolizável para crescimento diário $(\mathrm{MJ} / \mathrm{dia})$ é igual ao produto do ganho diário $(\mathrm{kg} / \mathrm{dia})$ pelo valor energético de cada $\mathrm{kg}$ ganho $(\mathrm{MJ} / \mathrm{kg})$, dividido pela eficiência de uso de EM para ganho $\left(\mathrm{K}_{\mathrm{f}}\right)$. $\mathrm{O}$ valor energético do ganho é função do peso e ganho de peso, com correções para maturidade de raças e classe de sexo.

No Cornel Net Carbohydrate and Protein System (CNCPS) os requerimentos para crescimento baseiamse na composição esperada do ganho do corpo vazio, em função do peso esperado à composição final, considerando porte, efeito de ingredientes dietéticos, energia, sexo e implantes anabólicos (FOX e BARRY, 1995).

As exigências de proteína dos ruminantes são atendidas pelos aminoácidos absorvidos em nível de intestino delgado, sendo estes provenientes principalmente da proteína microbiana e da proteína dietética não-degradada no rúmem. Atualmente, tanto o sistema americano (NRC, 1996) como o britânico (AFRC, 1993) calculam as exigências protéicas em termos de proteína metabolizável, ou seja, aminoácidos absorvidos no intestino delgado.

As exigências líquidas de proteína para bovinos em crescimento e engorda são função do conteúdo de matéria seca desengordurada do peso ganho, do peso vivo, do nível de ganho de peso, do grupo genético e do sexo. São menores para novilhos que para machos nãocastrados e para animais de raças de maturidade precoce que os de raças de maturidade tardia. Há tendência de decréscimo, no teor de proteína no ganho de peso, com o aumento do peso vivo do animal e, a dado peso vivo, com aumento da taxa de ganho de peso, reduzindo-se assim as necessidades protéicas em relação às necessidades energéticas (GEAY, 1984).

Objetivou-se, com o presente estudo, avaliar a composição corporal e do ganho de peso e as exigências de energia e proteína para ganho de peso de bovinos não castrados de quatro raças zebuínas ( Gir, Guzerá, Mocho-Tabapuã e Nelore) em confinamento.

\section{Material e Métodos}

Olocal, as instalações, os constituintes e composição da ração, o manejo dos animais, os procedimentos ao abate e metodologia de amostragem e análises laboratoriais foram descritos por PAULINO et al. (1999).

Os conteúdos corporais de gordura, proteína, água e macroelementos minerais foram determinados em função das concentrações percentuais destes em vísceras, órgãos, couro, sangue, cauda, cabeça e nos pés (gordura e osso) e componentes separados - músculos, gordura e osso - da seção HANKINS e HOWE (HH).

As análises químicas dos tecidos corporais iniciaram-se com a determinação dos teores de matéria seca gordurosa (MSG) e água. A amostra da MSG foi tratada com éter de petróleo (pré-desengorduramento) para obtenção da matéria seca pre-desengordurada (MSPD). Subtraindo-se a MSPD da MSG obteve-se a gordura extraída no pré-desengorduramento. A partir da MSPD moída, processaram-se as análises de proteína bruta, macrominerais e extrato etéreo residual. Conhecendo-se os teores da MSPD, obteve-se a composição química na matéria natural. Não se fez o pré-desengorduramento das amostras de sangue. O teor total de gordura da amostra foi obtido somando-se a gordura removida no prédesengorduramento com o extrato etéreo residual.

A partir das proporções de músculo, tecido adiposo e ossos na seção HH, determinou-se a proporção dos mesmos na carcaça, segundo as equações desenvolvidas por HANKINS e HOWE (1946):

Músculo: $\quad \hat{\mathrm{Y}}=16,08+0,80 \mathrm{X}$;

Tecido adiposo: $\hat{\mathrm{Y}}=3,54+0,80 \mathrm{X}$;

Ossos: $\quad \hat{\mathrm{Y}}=5,52+0,57 \mathrm{X}$;

em que

$\mathrm{X}$ é a porcentagem dos componentes na seção HH.

O peso do corpo vazio dos animais foi determinado pela soma do peso da carcaça, do sangue, da cabeça, do couro, da cauda, dos pés, das vísceras e dos órgãos.

A relação entre o peso do corpo vazio (PCVZ) e o peso vivo (PV) dos animais referências (AB), de cada raça, foi utilizada para estimar o PCVZ inicial dos animais da mesma raça, que foram abatidos posteriormente.

O conteúdo corporal de energia foi determinado a partir dos conteúdos corporais de proteína e gordura e dos respectivos equivalentes calóricos, conforme a equação abaixo (ARC, 1980):

$$
\mathrm{CE}(\mathrm{Mcal})=5,6405 \mathrm{X}+9,3929 \mathrm{Y}
$$

em que

$\mathrm{CE}=$ conteúdo de energia;

$\mathrm{X}=$ proteína corporal $(\mathrm{kg})$; e

$\mathrm{Y}=$ gordura corporal $(\mathrm{kg})$.

De modo a permitir a estimativa dos conteúdos de proteína, gordura e energia de animais dentro da faixa de pesos estudados, foram ajustadas equações de regres- 
são do logaritmo do conteúdo corporal de energia, gordura e proteína, em função do logarítmo do peso do corpo vazio (ARC, 1980), conforme o seguinte modelo:

em que

$$
Y_{i j}=\mu+b_{i} X_{i j}+e_{i j}
$$

$\mathrm{Y}_{\mathrm{ij}}=$ logaritmo do conteúdo total de energia (Mcal), gordura $(\mathrm{kg})$ ou proteína $(\mathrm{kg})$ retido no corpo vazio, do animal $\mathrm{j}$ do grupo genético $\mathrm{i}$;

$\mu$ = efeito da média (intercepto);

$b_{i}=$ coeficiente de regressão do logarítmo do conteúdo de energia ou proteína em função do logarítmo do peso do corpo vazio, para o grupo genético i, em que i=1, Gir; 2, Guzerá; 3, Nelore; 4, Mocho-Tabapuã;

$\mathrm{X}_{\mathrm{ij}}=$ logaritmo do peso do corpo vazio, do animal $\mathrm{j}$ do grupo genético i; e

$\mathrm{e}_{\mathrm{ij}}=$ erro aleatório.

$\mathrm{Na}$ determinação das equações de regressão, utilizou-se o programa LSMLMW, versão PC - 1, HARVEY (1987). As equações obtidas foram avaliadas quanto ao coeficiente de determinação (STEEL e TORRIE, 1960), e as comparações entre grupos genéticos foram realizadas de acordo com a metodologia adotada por GRAYBILL (1976), para testar identidade de modelos. Na análise de variância, utilizou-se o teste de $\mathrm{F}$ a $5 \%$ de probabilidade (PIMENTEL GOMES, 1982).

Para a conversão do $\mathrm{PV}$ em PCVZ, dentro do intervalo de pesos, incluídos no estudo, utilizou-se a equação obtida por regressão do PCVZ dos 63 animais utilizados no experimento, em função do PV dos mesmos.

Para conversão das exigências para ganho de PCVZ em exigências para ganho de peso vivo, utilizou-se o fator de 1,08 obtido por FONTES (1995), em condições brasileiras.

Derivando-se as equações de predição do conteúdo corporal de proteína, energia e mineral em função do logarítmo do PCVZ, obtiveram-se as equações de predição das exigências líquidas de proteína e energia, para ganho de $1 \mathrm{~kg}$ de PCVZ, do tipo:

$$
\mathrm{Y}^{\prime}=\mathrm{b} \cdot 10^{\mathrm{a}} \cdot \mathrm{X}^{(\mathrm{b}-1)}
$$

em que

$\mathrm{Y}^{\prime} \quad=$ exigência líquida de proteína $(\mathrm{kg})$ ou energia (Mcal);

a e $b=$ intercepto e coeficiente de regressão, respectivamente, das equações de predição dos conteúdos corporais de proteína ou energia; e

$\mathrm{X}=\mathrm{PCVZ}$ em $(\mathrm{kg})$.

As exigências de energia metabolizável (EM) foram determinadas utilizando-se a equação abaixo, segundo o AFRC (1993):

$$
\mathrm{EM}=(\mathrm{ELm} / \mathrm{k}) \cdot \ln (\mathrm{B} /(\mathrm{B}-\mathrm{R}-1)),
$$

em que

ELm= energia líquida de mantença, determinada neste estudo;

$\mathrm{K}=\mathrm{km} . \ln .(\mathrm{km} / \mathrm{kf})$;

$\mathrm{Km}=0,35 \mathrm{qm}+0,503$

$\mathrm{Kf}=0,78 \mathrm{qm}+0,006$;

$\mathrm{qm}=\mathrm{M} / 18,8$

$\mathrm{M}=\mathrm{MJ}$ de EM/kg de MS da ração. Utilizou-se no cálculo o valor de 10,12 MJ (2,42 Mcal) de EM por $\mathrm{kg}$ de MS, determinado neste estudo;

$B=\mathrm{km} /(\mathrm{km}-\mathrm{kf})$; e

$\mathrm{R}=\mathrm{ELg} / \mathrm{ELm}$, determinada neste estudo.

A energia digestível (ED) foi estimada a partir da $\mathrm{EM}$, considerando-se $\mathrm{ED}=\mathrm{EM} / 0,82$.

\section{Resultados e Discussão}

O teste de identidade de modelos (GRAYBILL, 1976), aplicado às equações de regressão do logaritmo do conteúdo corporal de proteína, gordura e energia, em função do logaritmo do PCVZ, para as quatro raças estudadas (Gir, Guzerá, Mocho - Tabapuã e Nelore), indicou não haver diferença entre as raças. Portanto, para se estimarem os conteúdos de proteína, gordura e energia no PCVZ, adotou-se equação geral comum às quatro raças (Tabela 1 ). Os coeficientes de determinação das equações de regressão $\left(\mathrm{r}^{2}\right)$ para proteína, gordura e energia variaram entre 0,81 e 0,89 , sendo semelhantes aos valores encontrados por LANA et al. (1992 a,b) e PIRES et al. (1993 a,b), que utilizaram a mesma metodologia, mostrando bom ajustamento das equações aos dados experimentais.

Tabela 1 - Parâmetro da regressão do $\log _{10}$ do conteúdo corporal de proteína $(\mathrm{kg})$, gordura $(\mathrm{kg})$ e energia (Mcal) em função do $\log _{10}$ do PCV, para animais das raças zebuínas

Table 1 - Parameter of regression of $\log _{10}$ of body content of protein (kg), fat ( $\mathrm{kg})$ and energy (Mcal), on EBW $\log _{10}$, for animals from the of Zebu breeds

Componente Parâmetro da regressão

Component

\begin{tabular}{ccc}
\multicolumn{3}{c}{ Parameter of regression } \\
$\begin{array}{c}\text { Intercepto } \\
\text { Intercept }\end{array}$ & $\beta$ & $\mathrm{r}^{2}$ \\
$-0,30710$ & 0,819902 & 0,89
\end{tabular}

\begin{tabular}{llll}
\hline $\begin{array}{l}\text { Proteína } \\
\text { Protein }\end{array}$ & $-0,30710$ & 0,819902 & 0,89 \\
$\begin{array}{l}\text { Gordura } \\
\text { Fat }\end{array}$ & $-4,098664$ & 2,318590 & 0,81 \\
$\begin{array}{l}\text { Energia } \\
\text { Energy }\end{array}$ & $-1,53581$ & 1,773221 & 0,89 \\
\hline
\end{tabular}


A inexistência de diferenças entre as quatro raças guarda coerência com os dados de JORGE et al. (1996), que analisando a composição física da carcaça dos animais usados no presente trabalho, concluíram não haver diferença entre as raças quanto as proporções estimadas de músculos, gordura e ossos.

Os conteúdos corporais totais de proteína (PBT) e gordura (GT), bem como os conteúdos de proteína, gordura e energia por quilograma do corpo vazio, estimados por intermédio das equações de regressão para animais com pesos vivos de 300 a $500 \mathrm{~kg}$, são apresentados na Tabela 2. Observa-se que o conteúdo total de proteína e gordura aumentou à medida que o peso vivo se elevou. Por outro lado, em termos de concentrações, ou seja, em $\mathrm{g} / \mathrm{kg}$ de PCVZ ou $\mathrm{Mcal} / \mathrm{kg}$ de PCVZ, com a elevação do peso corporal, há decréscimo no conteúdo corporal de proteína e aumento na concentração de gordura, com incremento paralelo no conteúdo de energia. Resultados semelhantes foram obtidos por REID e ROBB (1971), TEIXEIRA (1984), GONÇALVES (1988), LANA et al. (1992 a,b), PIRES et al. (1993 a,b), FREITAS (1995); FONTES (1995) e ESTRADA (1996). Estes resultados são concordantes com os resultados do ARC (1980), os quais indicaram variações nas proporções de gordura de 197 para $295 \mathrm{~g} / \mathrm{kg}$ de PCVZ; de proteína de 167 para $158 \mathrm{~g} / \mathrm{kg}$ de PCVZ; e de energia de 2,79 para 3,66 Mcal/kg de PCVZ, quando o PCVZ se elevou de 300 para $500 \mathrm{~kg}$.

A relação G/PB salienta as mudanças na composição dos tecidos depositados que acompanham a elevação do peso do animal, havendo desaceleração do crescimento muscular e desenvolvimento mais rápido do tecido adiposo (GRANT e HELFERICH, 1991). Os conteúdos corporais de gordura e energia verificados no presente trabalho são inferiores e os de proteína superiores aos relatados pelo ARC (1980).
As diferenças entre os resultados são parcialmente explicadas pelo fator sexo. Os dados do ARC (1980) referem-se a animais castrados, que depositam gordura mais precocemente no corpo, que animais nãocastrados, utilizados no presente trabalho. Este fato pode ser influenciado, também, pelo conteúdo moderado de energia metabolizável da ração $(2,42 \mathrm{Mcal} / \mathrm{kg}$ de MS), o que enseja menor acúmulo de gordura corporal.

Considerando-se um animal de $400 \mathrm{~kg}$ de PV, os resultados do presente estudo mostram conteúdos de $172 \mathrm{~g}$ de proteína, $174 \mathrm{~g}$ de gordura e 2,64 Mcal de energia por kg de PCVZ. Estes dados são bastante semelhantes aos encontrados por FREITAS (1995) e ESTRADA (1996), para animais Nelores, ao utilizarem metodologia semelhante à empregada neste trabalho. Em relação aos dados de FONTES (1995), que avaliou os resultados de vários experimentos com metodologias semelhantes, os conteúdos corporais de proteína, gordura e energia do presente estudo foram 6,$52 ; 19,44 ;$ e $12,87 \%$ inferiores, respectivamente, tendo como referência animal Nelore não-castrado de $400 \mathrm{~kg}$ de peso vivo.

Ao se derivarem as equações de regressão do logaritmo do conteúdo corporal de gordura, proteína e energia, em função do logaritmo do PCVZ, obtiveram-se as equações de predição dos conteúdos de gordura, energia e proteína por $\mathrm{kg}$ de ganho de PCVZ (Tabela 3). No que se refere à proteína e energia, esses conteúdos correspondem às exigências líquidas para ganho de $1 \mathrm{~kg}$ de PCVZ. As exigências líquidas de proteína e energia, e os conteúdos de gordura por $\mathrm{kg}$ de ganho de PCVZ e a relação G/PB no ganho, para animais zebuínos com pesos vivos de 300 a $500 \mathrm{~kg}$, encontram-se na Tabela 4.

Em relação aos animais da raça Nelore utilizados em trabalhos conduzidos usando metodologia semelhante, os dados referentes à proteína do presente

Tabela 2 - Composição corporal total de proteína (PT) e gordura (GT), conteúdo de proteína, gordura e energia e relação dos conteúdos de gordura e proteína $(\mathrm{G} / \mathrm{PB})$, para animais das quatro raças zebuínas

Table 2 - Total body protein (TP) and total fat (TF) composition, protein (CP), fat (F) and energy content, and fat:protein ratio (F/CP), for animals from the Zebu breeds

\begin{tabular}{|c|c|c|c|c|c|c|c|}
\hline PV & PCVZ & PT & GT & PB & G & G/PB & Energia \\
\hline$L W$ & $E B W$ & $T P$ & $T F$ & $C P$ & $F$ & $F / C P$ & Energy \\
\hline \multirow[t]{2}{*}{ (kg) } & $(\mathrm{kg})$ & $(\mathrm{kg})$ & (kg) & & $(\mathrm{g} / \mathrm{kgPCV})$ & & (Mcal/kgPCV) \\
\hline & & & & & $(g / k g E B W)$ & & $(\mathrm{Mcal} / \mathrm{kg} E B W)$ \\
\hline 300 & 246,9 & 45,1 & 28,1 & 183 & 114 & 0,623 & 2,06 \\
\hline 350 & 293,7 & 52,0 & 42,0 & 177 & 143 & 0,808 & 2,36 \\
\hline 400 & 340,6 & 58,8 & 59,2 & 172 & 174 & 1,012 & 2,64 \\
\hline 450 & 387,4 & 65,3 & 79,8 & 168 & 206 & 1,226 & 2,92 \\
\hline 500 & 434,3 & 71,7 & 104,1 & 165 & 240 & 1,454 & 3,19 \\
\hline
\end{tabular}


Tabela 3 - Regressão de predição do ganho de proteína, gordura e energia por kg ganho de PCVZ para animais das raças zebuínas

Table 3 - Prediction regression for protein, fat and energy gain per $\mathrm{kg}$ of EBW gain for animals from the Zebu breeds

Componente Regressão de predição

Proteína ${ }^{1}$ Prediction regression

Protein

Gordura $^{1}$

Fat

Energia $^{2}$

Energy

1 (kg/kg de ganho PCV) (kg/kg EBW gain).

2 (Mcal/kg de ganho PCV) (Mcal/kg EBW gain). trabalho apresentam magnitude semelhante aos de ESTRADA (1996), são inferiores aos de PIRES et al. (1993a) e superiores aos de FREITAS (1995) e LANA et al. (1992 a,b). A diferença em relação aos dados de LANA et al. (1992a,b) é explicada, em parte, pela condição sexual dos animais, uma vez que esse autor trabalhou com animais castrados.

Quanto ao conteúdo de gordura e energia, os dados do presente trabalho assemelham-se aos de ESTRADA (1990) e são inferiores aos de LANA et al. (1992a,b) e PIRES et al. (1993a,b), para animais Nelore. Sabe-se que os animais castrados têm maior

Tabela 4 - Conteúdo de gordura e exigência líquida de energia e proteína por kg de ganho de PCVZ e relação gordura/proteína (G/P) no ganho para animais das raças zebuínas

Table 4 - Content of fat and net energy and protein requirement per $\mathrm{kg}$ of EBW gain and fat/protein ratio for animals from the Zebu breeds

\begin{tabular}{|c|c|c|c|c|c|}
\hline \multirow{3}{*}{$\begin{array}{l}\text { Componente } \\
\text { Component }\end{array}$} & \multicolumn{5}{|c|}{$\mathrm{PV} / \mathrm{PCVZ}(\mathrm{kg})$} \\
\hline & \multicolumn{5}{|c|}{$L W / E B W$} \\
\hline & $300 / 246,9$ & $350 / 293,7$ & $400 / 340,6$ & $450 / 387,4$ & $500 / 434,3$ \\
\hline Gordura $^{1}$ & 263 & 330 & 402 & 476 & 553 \\
\hline Fat & & & & & \\
\hline Energia $^{2}$ & 3,65 & 4,18 & 4,69 & 5,18 & 5,66 \\
\hline Energy & & & & & \\
\hline Proteína ${ }^{1}$ & 150 & 145 & 141 & 138 & 135 \\
\hline Protein & & & & & \\
\hline Relação G/P & 1,75 & 2,28 & 2,85 & 3,45 & 4,10 \\
\hline
\end{tabular}

1 (kg/kg de ganho PCVZ) (kg/kg EBW gain)

2 (Mcal/kg de ganho PCVZ) (Mcal/kg EBW gain)

tendência a depositar gordura, o que explica, em parte, as diferenças em relação aos dados de LANA et al. (1992a, b).

Com relação aos resultados de FONTES (1995), que analisou os dados de vários experimentos em conjunto, e tomando como referência um animal Nelore não-castrado de $400 \mathrm{~kg}$ de PV, os valores aqui encontrados são 6,14 e 1,3\% inferiores para proteína, gordura e energia, respectivamente. Em relação aos dados de BOIN (1995), as exigências líquidas de energia e proteína para ganho de $1 \mathrm{~kg}$ de PCVZ, do presente estudo, são $7 \%$ superiores e $22 \%$ inferiores, respectivamente.

As exigências de energia líquida para ganho de $1 \mathrm{~kg}$ de peso de corpo vazio, para um animal de $400 \mathrm{~kg}$ de $\mathrm{PV}$, são $10 \%$ inferiores às do ARC (1980) para animais não-castrados de porte médio. As estimativas de exigências líquidas de energia e proteína para ganho de $1 \mathrm{~kg}$ de peso vivo encontram-se na Tabela 5 .
Os requerimentos de energia líquida para um animal de $400 \mathrm{~kg}$ de PV (4,34 Mcal) são 5,29\% inferiores aos preconizados pelo NRC (1996) (4,57 Mcal) para animais de estrutura média de peso semelhante. Por outro lado, o NRC (1996) apresenta valor de exigência de proteína metabolizável para ganho de $1 \mathrm{~kg}$ de peso vivo de $272 \mathrm{~g} /$ dia, para animais de porte médio. Usando-se a eficiência de utilização de proteína metabolizável para ganho de peso de 0,492, adotada por esse conselho, calcula-se a exigência de proteína líquida como sendo $134 \mathrm{~g} / \mathrm{dia}$, valor 2,29\% inferior ao encontrado no presente trabalho ( $131 \mathrm{~g} / \mathrm{animal} / \mathrm{dia})$.

As estimativas de exigências líquidas totais de energia e as exigências dietéticas, em termos de energia metabolizável e energia digestível, encontramse na Tabela 6 . As exigências de energia metabolizável $(19,01 \mathrm{Mcal} / \mathrm{animal} / \mathrm{dia})$ para um animal de $400 \mathrm{~kg}$ de PV são praticamente iguais às preconizadas pelo 
Tabela 5 - Exigência líquida de energia e proteína por kg PV ganho, de animais das raças zebuínas, em função do PV ou PCV

Table 5 - Net requeriments of energy and protein per kg LW gain, for animals from the four Zebu breeds in function of $L W$ or EBW

\begin{tabular}{lccc}
\hline PV & PCV & Proteína & Energia \\
$L W$ & $E B W$ & $\begin{array}{c}\text { Protein } \\
(\mathrm{g})\end{array}$ & $\begin{array}{c}\text { Energy } \\
(\mathrm{Mcal})\end{array}$ \\
\hline $\mathrm{kg})$ & $(\mathrm{kg})$ & 139 & 3,38 \\
300 & 246,9 & 135 & 3,87 \\
400 & 293,7 & 131 & 4,34 \\
450 & 340,6 & 128 & 4,80 \\
500 & 387,4 & 125 & 5,24 \\
\hline
\end{tabular}

AFRC (1993), ou seja, 19,12 Mcal/animal/dia.

Em relação aos dados obtidos no Brasil, as exigências de energia metabolizável para um animal de $400 \mathrm{~kg}$ de peso vivo são $15 \%$ inferiores aos de ESTRADA (1996) para animais não-castrados da raça Nelore. Cumpre salientar que nos cálculos do presente trabalho utilizou-se valor de exigência de mantença determinada experimentalmente, que foi inferior ao usado pelo autor anterior. Em relação aos dados de autores que determinaram as exigências de mantença experimentalmente e utilizaram metodologia semelhante, os dados do presente trabalho são $29 \mathrm{e}$ $10 \%$ superiores aos de PIRES et al. (1993b) e FREITAS (1995), respectivamente.

Tabela 6 - Exigêncialíquida de energia para mantença(ELm), para ganho de peso (ELg) e total (ELt), energia metabolizável (EM) e energia digestível (ED), em Mcal/animal•dia, para animais das raças zebuínas, em função do PV ou do PCV

Table 6 - Net requirement of energy for maintenance (NEm), weight gain (NEg) and total (NEt), metabolizable energy (ME) and digestible energy (DE) for animals from the Zebu breeds, in function of $L W$ orEBW

\begin{tabular}{lcccccc}
\hline PV & PCV & Elm* & ELg & Elt & EM & ED \\
$L W$ & $E B W$ & $N E m$ & $N E g$ & $N E t$ & $M E$ & $D E$ \\
\cline { 3 - 7 }$(\mathrm{kg})$ & $(\mathrm{kg})$ & \multicolumn{5}{c}{ Mcal/animal } \\
\hline 300 & 246,9 & 4,35 & 3,38 & 7,73 & 14,89 & 18,16 \\
350 & 293,7 & 4,89 & 3,87 & 8,76 & 16,99 & 20,72 \\
400 & 340,6 & 5,40 & 4,34 & 9,74 & 19,01 & 23,18 \\
450 & 387,4 & 5,90 & 4,80 & 10,70 & 20,99 & 25,60 \\
500 & 434,3 & 6,38 & 5,24 & 11,62 & 22,88 & 27,90 \\
\hline
\end{tabular}

\section{Conclusões}

As raças não diferiram entre si, quanto ao conteúdo corporal de gordura, proteína e energia.

As exigências de proteína e energia líquidas para ganho de peso foram semelhantes às adotadas pelo NRC (1996).

As exigências de energia metabolizável para ganho de peso foram semelhantes às adotadas pelo AFRC (1993).

\section{Referências Bibliográficas}

AGRICULTURAL AND FOOD RESEARCH COUNCIL - AFRC. 1993. Energy and protein requeriments of ruminants: Commonwealth Agricultural Bureaux International. 159p.

AGRICULTURAL RESEARCH COUNCIL - ARC. 1980. The nutrient requirements of ruminants livestock: Commonwealth Agricultural Bureaux. 351p.

BOIN, C. Alguns dados sobre exigências de energia e de proteína de zebuínos. In: SIMPÓSIO INTERNACIONAL SOBRE EXIGÊNCIAS NUTRICIONAIS DE RUMINANTES, 1995, Viçosa, MG. Anais... Viçosa, 1995. p.457-465.

ESTRADA, L. H. C. Composição corporal e exigências de proteina, energia e macroelementos minerais ( $\mathrm{Ca}, \mathrm{P}, \mathrm{Mg}, \mathrm{Na}$ e K), características da carcaça e desempenho do nelore e mestiços em confinamento. Viçosa: UFV, 1996. 129p. Tese (Doutorado em Zootecnia) - Universidade Federal de Viçosa, 1996.

FONTES, C. A. A. Composição corporal, exigências líquidas de nutrientes para ganho de peso e desempenho produtivo de animais zebuínos e mestiços europeu-zebu. Resultados experimentais. In: SIMPÓSIO INTERNACIONAL SOBRE EXIGÊNCIAS NUTRICIONAIS DE RUMINANTES, 1995, Viçosa, MG. Anais...Viçosa, 1995, p.419-455.

FOX, D. G., BARRY, M.C. Predicting nutrient requirements and supply for cattle with the Cornell net carbohydrate and protein system. In: SIMPÓSIO INTERNACIONAL SOBRE EXIGÊNCIAS NUTRICIONAIS DE RUMINANTES, 1995, Viçosa, MG. Anais... JARD, 1995, p.77-101.

FREITAS, J. A. Composição corporal e exigência de energia e proteina de bovinos (zebuínos e mestiços) e bubalinos não castrados, em confinamento. Viçosa, MG: UFV,1995. 132p. Dissertação (Mestrado em Zootecnia) - Universidade Federal de Viçosa, 1995.

GARRETT, W. N. 1980. Factors influencing energetic efficiency of beef production. J. Anim. Sci., 51(6):1434-1440.

GARRETT, W. N., MEYER, J.H., LOFGREEN, G. P. 1959. The comparative energy requeriments of sheep and cattle for maintenance and gain. J. Anim. Sci., 18(2):528-47.

GEAY, Y. 1984. Energy and protein utilization in growing cattle. J. Anim. Sci., 58(3):766-778.

GONÇALVES, L.C. Digestibilidade, composição corporal, exigências nutricionais e características das carcaças de zebuinos, taurinos e bubalinos. Viçosa, MG: UFV, 1988. 238p. Tese (Doutorado em Zootecnia) - Universidade Federal de Viçosa, 1988.

GRANT, A.L., HELFERICH, W. G. 1991. An overview of growth. In: PEARSON, A. M. DUTSON, T. R. (Eds.) Growth regulation in farm animals. Elsevier Applied Science, p.1-5.

GRAYBILL, F.A. 1976. Theory and aplication of the linear model. Massachussetts: Duxburg Press. 704p. 
HANKINS, O. G., HOWE, P.E. 1946. Estimation of the composition of beef carcasses and cuts (Tech. Bulletin - USDA, 926). 20p.

HARVEY, W. R. 1987. Mixed model least squares and maximum likelihood computer program (LSMLWM) Versão PC - 1.

JORGE, A.M., FONTES, C.A.A., PAULINO, M.F. Composição física, e outras características quantitativas de carcaças de zebuínos não castrados de quatro raças, abatidas em três estágios de maturidade. In: SOCIEDADE BRASILEIRA DE ZOOTECNIA, 33, 1996, Fortaleza. Anais... Fortaleza: SBZ, 1996. p.188-190.

LANA, R.P., FONTES, C.A.A., PERON, A.J. et al. 1992a. Composição corporal e exigências de energia, proteína e macroelementos minerais ( $\mathrm{Ca}, \mathrm{P}, \mathrm{Mg}, \mathrm{Na}$ e $\mathrm{K}$ ) de novilhos de cinco grupos raciais em confinamento. 1. Conteúdo corporal e do ganho de peso em gordura, proteína e energia. $R$. Soc. Bras. Zootec., 21(3):518-527.

LANA, R.P., FONTES, C.A.A., PERON, A.J. et al. 1992 b. Composição corporal e exigências de energia, proteína e macroelementos minerais ( $\mathrm{Ca}, \mathrm{P}, \mathrm{Mg}, \mathrm{Na}$ e K) de novilhos de cinco grupos raciais em confinamento. 2. Exigências de energia e proteína. R. Soc. Bras. Zootec., 21(3):528-537.

NATIONAL RESEARCH COUNCIL - NRC. 1984. Nutrient requeriments of beef cattle. 6 . ed., $90 \mathrm{p}$.

NATIONAL RESEARCH COUNCIL - NRC. 1996. Nutrient requirements of beef cattle. 7.ed., 242p.

PAULINO, M. F., FONTES, C.A.A., JORGE, A. M. et al. 1999. Exigências de energia para mantença de bovinos não-castrados de quatro raças zebuínas em confinamento. R. Bras. Zootec., 28(3):639-645.

PERON, A. J., FONTES, C. A. A., LANA, R. P. et al. 1993a. Rendimento da carcaça e de seus cortes básicos e área corporal de bovinos de cinco grupos genéticos, submetidos a alimentação restrita e "ad libitum". R. Soc. Bras. Zootec., 22(2):238-47.

PERON, A. J., FONTES, C. A. A., LANA, R. P. et al. 1993 b. Tamanho de órgãos internos e distribuição da gordura corporal, em novilhos de cinco grupos genéticos, submetidos a alimentação restrita e "ad libitum". R. Soc. Bras. Zootec., 22(5):813-19.
PIMENTEL GOMES, F. 1982. Curso de estatística experimental. Piracicaba: Livraria Nobel. 430p.

PIRES, C.C., FONTES, C.A.A., GALVÃO, J.G. et al. 1993a. Exigências nutricionais de bovinos de corte em acabamento. I. Composição corporal e exigências de proteína para ganho de peso. R. Soc. Bras. Zootec., 22(1):110-120.

PIRES, C.C., FONTES, C.A.A., GALVÃO, J.G. et al. 1993b. Exigências nutricionais de bovinos de corte em acabamento. II. Exigências de energia para mantença e ganho de peso. $R$. Soc. Bras. Zootec., 22(1):121-32.

REID, J.T., ROBB, J. 1971. Relationship of body composition to energy intake and energetic efficiency. J. Dairy Sci., 54(4):553-64.

STEEL, R.G.D., TORRIE, J.H. 1960. Principles and procedures of statistics. New York: McGraw-Hill Book Company. 481p.

TEIXEIRA, J. C. Exigências de energia e proteína, composição eárea corporal e principais cortes da carcaça em seis grupos genéticos de bovídeos. Viçosa, MG: UFV, 1984. 94p. Dissertação (Mestrado emZootecnia)-Universidade Federal de Viçosa, 1984.

Recebido em: 04/03/98

Aceito em: 04/12/98 